Muhammad Ali Javed, Elmar Baumhögger, Jadran Vrabec

\title{
Thermodynamic Speed of Sound Data for Liquid and Supercritical Alcohols
}

Journal article | Accepted manuscript (Postprint)

This version is available at https://doi.org/10.14279/depositonce-8387

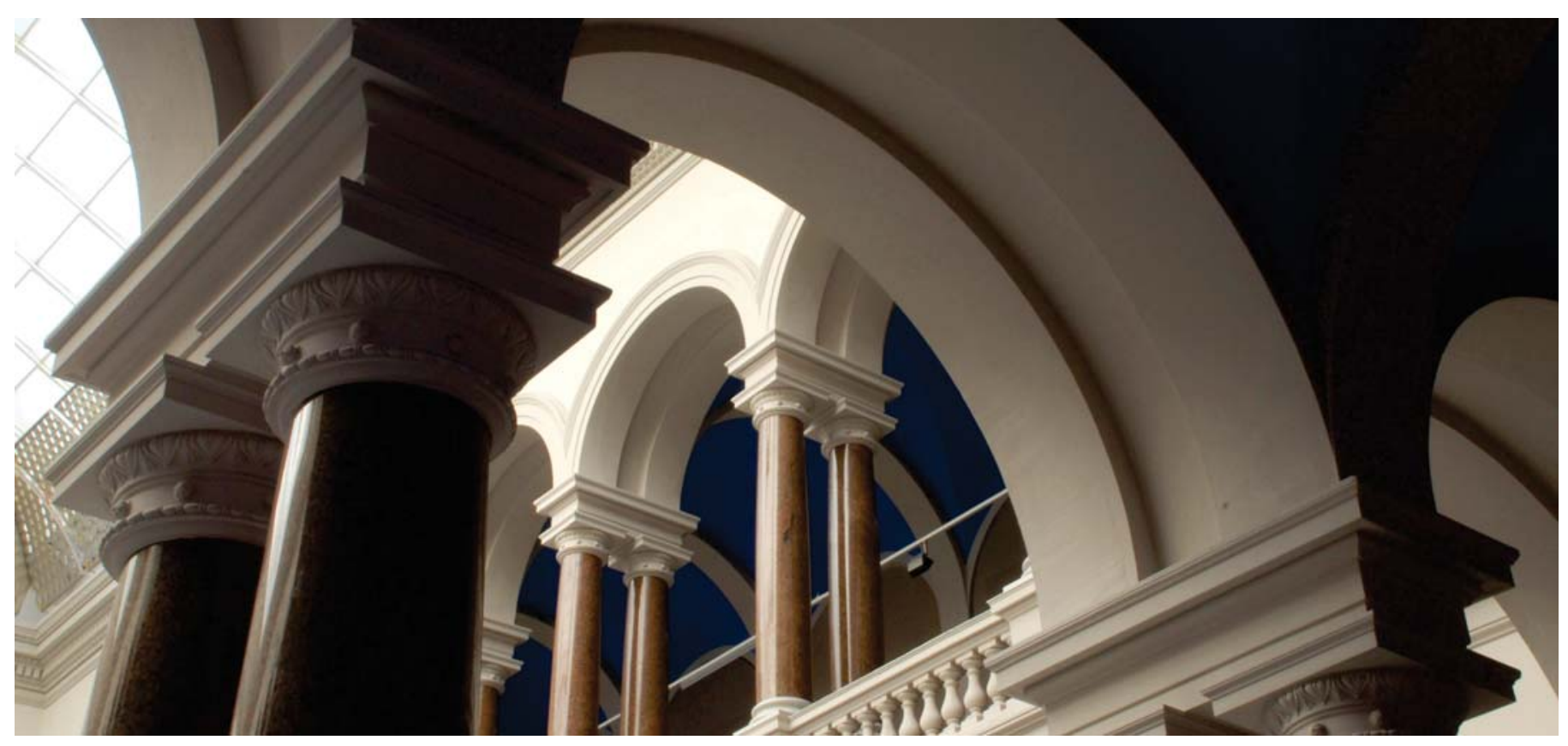

Javed, Muhammad Ali; Baumhögger, Elmar; Vrabec, Jadran (2019). Thermodynamic Speed of Sound Data for Liquid and Supercritical Alcohols. J ournal of Chemical \& Engineering Data, 64(3), 1035- 1044. https://doi.org/10.1021/acs.jced.8b00938 


\title{
Thermodynamic speed of sound data for liquid and supercritical alcohols
}

\author{
Muhammad Ali Javed ${ }^{\dagger}$, Elmar Baumhögger $\stackrel{\perp}{ }$, Jadran Vrabec ${ }^{+*}$ \\ † Thermodynamics and Process Engineering, Technical University of Berlin, 10623 Berlin, Germany \\ ${ }^{\perp}$ Thermodynamics and Energy Technology, University of Paderborn, 33098 Paderborn, Germany
}

\begin{abstract}
Because of their caloric and thermal nature, speed of sound data are vital for the development of fundamental Helmholtz energy equations of state for fluids. The present work reports such data for methanol, 1-propanol, 2-propanol and 1-butanol along seven isotherms in the temperature range from $220 \mathrm{~K}$ to $500 \mathrm{~K}$ and a pressure of up to $125 \mathrm{MPa}$. The overall expanded uncertainty varies between $0.07 \%$ and $0.11 \%$ with a confidence level of $95 \%$. The employed experiment is based on a double path length pulse-echo method with a single piezoelectric quartz crystal of $8 \mathrm{MHz}$, which is placed between two reflectors at different pathlengths. Measured speed of sound data for the four alcohols are fitted with double polynomial equations and compared with literature sources.
\end{abstract}

\section{Introduction}

Although it plays an important role in the transport of pressure oscillations through matter, the speed of sound is a thermodynamic equilibrium property. This can directly be seen from its definition

$w=\sqrt{(\partial p / \partial \rho)_{s}}$

where $w$ is the speed of sound, $p$ the pressure, $\rho$ the density and $s$ the entropy. It thus relates pressure to density variations under isentropic conditions, which are given for reversible processes in the absence of heat transfer. In case of typical sound emission scenarios, where amplitude and frequency are not excessive, ${ }^{1}$ data on wave propagation timing indeed adhere to definition (1).

Because of the isentropic condition of the partial derivative in its definition (1), the speed of sound is not a purely thermal property. Instead, it contains information on the caloric behavior of matter. A less common expression for the speed of sound can be given in terms of the Helmholtz energy $y^{2,3}$

$w^{2} / T=1+2 A_{01}^{r}+A_{02}^{r}-\frac{\left(1+A_{01}^{r}-A_{11}^{r}\right)^{2}}{A_{20}^{0}+A_{20}^{r}}$

Therein, $T$ is the temperature and $A_{m n}$ represent a normalized form of partial derivatives of the Helmholtz energy with respect to inverse temperature and density. ${ }^{3}$ Subscript $m$ stands for the order of the inverse temperature derivative and $n$ for the order of the density derivative. In case of an ideal gas, the residual Helmholtz energy (superscript $r$ ) vanishes, while the ideal contribution (superscript 0 ) remains. Consequently, the wellknown equation for the ideal gas emerges ${ }^{4}$

$w^{0}=\sqrt{\kappa R T}$,

where $R$ stands for the gas constant and $\kappa$ is the heat capacity ratio. From equation (3), the caloric nature of the speed of sound becomes evident.
In general, measuring thermodynamic properties is a tedious and time-consuming undertaking, especially at elevated temperatures and pressures. However, speed of sound measurements can be accomplished comparably rapidly and yield data with a high accuracy. E.g., in the present work, about four weeks were required to measure one fluid in the considered temperature and pressure ranges.

Due to their caloric and thermal nature, temperature and pressure dependent speed of sound data can be integrated to yield both density and isobaric heat capacity. Properties calculated along that route may often be more reliable than direct measurements. $^{5}$

Speed of sound data have also been used extensively as a basis for the development and parameterization of fundamental Helmholtz energy equations of state for fluids. ${ }^{6,7}$ With these models, all time-independent thermodynamic properties can be calculated efficiently, i.e. without integration.

The aim of this work was to provide accurate speed of sound data for a group of primary alcohols, which are commonly used in numerous applications and industrial processes, e.g. as fuels, solvents, inhibitors, heat transfer agents or paint additives. ${ }^{8-12}$ Consequently, precise thermodynamic data are needed for these alcohols over a wide span of temperature and pressure to develop high-quality Helmholtz energy equations of state. ${ }^{7,13,14}$ Moreover, such data are important to validate speed of sound calculations by means of thermodynamic models. ${ }^{15-18}$

In this work, the pulse-echo technique was implemented to measure speed of sound of methanol, 1-propanol, 2-propanol and 1-butanol. Ethanol was omitted from this series because it was measured extensively in the past. Data are presented in the temperature range 220 to $500 \mathrm{~K}$ up to a pressure of $125 \mathrm{MPa}$. In the open literature, only scattered data were available especially at elevated temperatures and pressures as depicted in Figure 1. To strengthen the database of experimental results, precise speed of sound data with a maximum expanded uncertainty $(k$ $=2$ ) of up to $0.11 \%$ are reported. The present experimental results were fitted with a double polynomial equation and compared with literature data. 


\section{Experiment}

\subsection{Materials}

The fluids under investigation were purchased at high purity and used without any further purification, except for degassing the reference fluid (water) and the alcohols. Details are provided in Table 1.

\subsection{Apparatus and experimental procedure}

The measuring principle of the employed experimental setup was based on the pulse-echo technique, which is the most common method to measure the speed of sound of liquids and compressed gases ${ }^{19}$. Details of the experimental rig were already provided in our recent publications ${ }^{6,20,21}$ so that only a short overview is given here. To bring the pulse-echo technique into practice, a piezoelectric quartz crystal with a diameter of $15 \mathrm{~mm}$ and a resonance frequency of $8 \mathrm{MHz}$ was used as a transducer. The quartz crystal was mounted between two polished reflectors and excited electrically by sinusoidal burst signals to generate ultrasonic sound waves.

Two waves propagate in opposite directions through the sample fluid over known distances. After reflection, they interact with the quartz crystal, which also acts as a receiver of the sound waves, cf. Figure 2 . The distance between quartz crystal and reflector 1 was $l_{l} \approx 20 \mathrm{~mm}$ and reflector 2 was $l_{2} \approx 30 \mathrm{~mm}$. Because of the difference between the propagation lengths, the two echoes were received at different times $t_{1}$ and $t_{2}$, where $\Delta t=t_{2}$ - $t_{l}$. A high-resolution digital oscilloscope was used to monitor the timing of the echoes received by the quartz crystal. Neglecting diffraction and dispersion effects, the speed of sound was calculated by

$$
w=2\left(l_{2}-l_{1}\right) / \Delta t .
$$

The acoustic path length difference of the sensor $\Delta l=l_{2}-l_{1}$ was calibrated with pure water. It was used as a reference because it is a particularly well studied fluid ${ }^{22-24}$ and available at very high purity. Moreover, highly precise data for the speed of sound were reported by Lin and Trusler ${ }^{19}$ with an uncertainty of $0.04 \%$ and the reference quality equation of state by Wagner and $\operatorname{Pru} \beta^{25}$ is available. The calibration procedure and the correction of the path length variation due to temperature and pressure has been described in detail in preceding work $^{6}$. The change in path length was considered by

$$
\Delta l_{T, p}=\Delta l_{T_{0}, p_{0}}\left(1+\alpha\left(T-T_{0}\right)+\frac{1}{E}(1-2 v)\left(p_{0}-p\right)\right) \text {. }
$$

Therein, $\Delta l_{T 0, p 0}$ is the calibrated path length at $T_{0}=300 \mathrm{~K}$ and $p_{0}=1.29 \mathrm{MPa}, \alpha$ the linear thermal expansion coefficient, $E$ the elastic modulus and $v$ the Poisson number.

Figure 3 shows that the present calibration measurements are convincingly consistent with the experimental data by Lin and Trusler ${ }^{19}$ and the equation of state by Wagner and Pru $\beta .^{25}$ The present data even show a better agreement with the reference equation of state at high pressures. All measured state points agree almost within $0.02 \%$, except for one with a deviation of $0.05 \%$.

Before filling the sampled fluid in to the measurement cell, it was evacuated for two hours.

\section{Results and discussion}

The speed of sound of the alcohols was measured for liquid and supercritical states along seven isotherms, i.e. $220 \mathrm{~K}, 250$ $\mathrm{K}$ and with an increment of $50 \mathrm{~K}$ up to $500 \mathrm{~K}$. The pressure was varied from 0.1 MPa up to $125 \mathrm{MPa}$ for 2-propanol and three isotherms for methanol. The maximum pressure was $80 \mathrm{MPa}$ for the remaining isotherms of methanol, 1-propanol and 1-butanol because of pressure vessel leakage problems. Since there was no equation of state of high accuracy available for 1-propanol, 2-propanol and 1-butanol, a double polynomial expression suggested by Sun et al. ${ }^{26}$ was implemented to fit the present experimental data for the alcohols

$p-p_{0}=\sum_{i=1}^{3} \sum_{j=0}^{2} a_{i j}\left(u-u_{0}\right)^{i} T^{j}$.

Therein, the initial pressure is $p_{0}=0.1 \mathrm{MPa}$ and $u_{0}$ is the speed of sound at $p_{0}$. The temperature dependence of $u_{0}$ was fitted with a polynomial

$u_{0}=\sum_{j=0}^{6} b_{j} T^{j}$,

where $a_{i j}$ and $b_{j}$ are coefficients that are independent of temperature and pressure. To determine the fitting quality, the average percentage deviation was calculated by

$A A D=\frac{100}{n} \sum_{i=1}^{n}\left|\frac{w_{\text {data }}-w_{\text {equation }}}{w_{\text {data }}}\right|_{i}$

where $n$ is the number of experimental data points. Deviations of experimental literature data from equation (6) were calculated by

$\Delta w=100 \frac{w_{\text {data }}-w_{\text {equation }}}{w_{\text {data }}}$.

To correlate present experimental data, equation (7) was fitted first to speed of sound data at $p_{0}$ to obtain the coefficients $b_{j}$ and subsequently equation (6) was fitted to all speed of sound data by minimizing the quadratic sum of the difference between the experimental and calculated speed of sound. For the high temperature isotherms, i.e. $450 \mathrm{~K}$ and $500 \mathrm{~K}$, it was not possible to measure $u_{0}$ because the alcohols are supercritical. Instead, for these high temperature isotherms, equation (6) was fitted first to these individual isotherms to estimate $u_{0}$ values, which were then used in equation (7) in an iterative way. The coefficients of equations (6) and (7) along with the AAD are provided in Table 2. The performance of equation (6) for the alcohols is presented in Figure 4, where it is shown that all experimental speed of sound data are in good agreement with the speed of sound correlation (6). For low temperature isotherms, the speed of sound increases approximately linearly with pressure. At elevated temperatures and low pressures, a rapid change of the speed of sound was observed, i.e. $450 \mathrm{~K}$ and $500 \mathrm{~K}$ and pressures below $20 \mathrm{MPa}$. This sudden drop of the speed of sound is due to the proximity to the critical point of the alcohols.

The overall expanded speed of sound measurement uncertainty $U(w)$ is composed of the relevant contributions due to standard uncertainties of temperature $u(T)$ and pressure measurements $u(p)$, as well as the uncertainty of the path length difference $u(\Delta l)$ and the uncertainty of the time measurement $u(t)^{27}$

$$
U(w)=k\left[\begin{array}{l}
\left(\left(\frac{\partial w}{\partial T}\right)_{p, l, t} u(T)\right)^{2}+\left(\left(\frac{\partial w}{\partial p}\right)_{T, l, t} u(p)\right)^{2} \\
+\left(\left(\frac{\partial w}{\partial \Delta l}\right)_{p, T, t} u(\Delta l)\right)^{2}+\left(\left(\frac{\partial w}{\partial t}\right)_{p, l, T} u(t)\right)^{1 / 2}
\end{array}\right]^{2} .
$$

Assuming a coverage factor $k=2$ leads to a level of confidence of $95 \%$. According to the error propagation law, the total expanded uncertainty for data on the four alcohols varies between $0.07 \%$ and $0.11 \%$. 
A more detailed uncertainty budget is provided in Table 3. It includes information on the measurement devices used in the present work, along with the influence of their individual uncertainties on the speed of sound data. The provided uncertainty of the PT-25 thermometer was assumed to be ten times larger than its actual value because it was not in a direct contact with the fluid. ${ }^{6}$ To suppress the pressure uncertainty, three pressure transducers were used, possessing different operating ranges. Note that the sample purity was not considered in the uncertainty budget.

\subsection{Results for methanol}

Experimental speed of sound data for methanol with uncertainties are listed in Table 4. A comparison of the present data set, experimental literature values and the Helmholtz energy equation of state by De Reuck and Craven ${ }^{28}$ is shown in Figure 5 . An uncertainty of $2 \%$ for speed of sound values was specified by De Reuck and Craven ${ }^{28}$ for their equation of state. The AAD of the present experimental data from equation (6) is $0.24 \%$. Data measured by Dávila et al. ${ }^{29}$ with AAD of $0.15 \%$ almost exactly match with the present data at $250 \mathrm{~K}$ and $350 \mathrm{~K}$, considering their experimental uncertainty of $0.03 \%$. They also implemented the pulse-echo technique with a sample purity of $>99.9 \%$.

Several authors reported data near $300 \mathrm{~K}$ exhibiting the following AAD: Plantier et al., ${ }^{30} 0.50 \%$; Sun et al.,${ }^{31} 2.66 \%$; Wilson and Bradley, ${ }^{32} 0.76 \%$; Carnevale and Litovitz, ${ }^{33} 0.84 \%$ and Hawley et al. ${ }^{34} 6.33 \%$. Data by Plantier et al. ${ }^{30}$ with an uncertainty of $<0.20 \%$ are in good agreement with present speed of sound values at $300 \mathrm{~K}$. However, they show a systematic offset at $350 \mathrm{~K}$, but the deviations are almost within the cumulative experimental uncertainty of their and the present work. Moreover, their reported sample purity $>99 \%$ was lower than here. Data by Sun et al. ${ }^{31}$ and Wilson and Bradley ${ }^{32}$ with experimental uncertainties of $<0.04 \%$ and $<0.56 \mathrm{~m} \mathrm{~s}^{-1}$ also validate the present measurements. At some state points, data by Hawley et al. ${ }^{34}$ and Carnevale and Litovitz ${ }^{33}$ verify present values too, but these authors did not provide information on experimental uncertainty or sample purity.

The entire experimental dataset coincides well with equation (6), except for the data by Sun et al. ${ }^{31}$ at $350 \mathrm{~K}$. It seems that their data contain random errors at higher temperature. The equation of state by De Reuck and Craven ${ }^{28}$ is in a very good agreement with the experimental data at $300 \mathrm{~K}$, but it shows an offset for other isotherms, especially at low pressures. However, it is throughout consistent with the measured data, even for the highest isotherm, i.e. $500 \mathrm{~K}$. The equation of state contains information on the critical point and numerous other thermodynamic properties such that it can represent the speed of sound data efficiently. Nonetheless, the equation of state for methanol should be improved in the liquid and supercritical region by considering the present experimental results.

\subsection{Results for 1-propanol}

Experimental speed of sound data for 1-propanol with uncertainties are listed in Table 5. Deviations of experimental speed of sound data from equation (6) are shown in Figure 6. To the best of our knowledge, no experimental data were published for this substance for elevated temperatures and pressures. Speed of sound data for three isotherms were compared with the available literature data and the AAD of present data from equation (6) is $0.14 \%$. Most recent data reported by Dávila et al. ${ }^{29}$ (AAD $=0.07 \%$ ) with an experimental uncertainty of $0.013 \%$ and a sample purity of $99.9 \%$ are in good agreement with the present data at $300 \mathrm{~K}$ and $350 \mathrm{~K}$. Again, their data show a systematic offset at $250 \mathrm{~K}$, which is within the collective experimental uncertainty of both works.

Around $300 \mathrm{~K}$, speed of sound data were measured by different authors with the following AAD: Wilson and Bradley, ${ }^{32}$ 0.17\%; Marczak et al., ${ }^{5} 0.30 \%$; Dzida and Ernst, ${ }^{35} 0.27 \%$; Carnevale and Litovitz, ${ }^{33} 0.04 \%$; Hawley et al. ${ }^{34} 3.13 \%$; Sysoev and Otpushchennikov, ${ }^{36} 4.11 \%$; Hagelberg, ${ }^{37} 12.67 \%$. Results by Wilson and Bradley ${ }^{32}$ with an experimental uncertainty of $<0.56 \mathrm{~m} \mathrm{~s}^{-1}$ and a sample purity of $99.9 \%$ almost exactly match with present results. Data reported by Marczak ${ }^{5}$ and Dzida ${ }^{35}$ are in good agreement with present measurements, except for a single data point at $15.2 \mathrm{MPa}$. Both authors claimed an experimental uncertainty of $0.04 \%$ and a sample purity of $99.8 \%$. Measurements by Carnevale, ${ }^{33}$ Hagelberg $^{37}$ and Hawley ${ }^{34}$ confirm the present data at some state points too, but no information was provided on experimental uncertainty or sample purity.

All experimental results follow more or less a similar trend in the considered temperature and pressure range, except for the data by Sysoev and Otpushchennikov. ${ }^{36}$ Their data coincide with the other results at around $20 \mathrm{MPa}$, but the deviations are significant at higher and lower pressures. This trend can be seen most clearly for the $350 \mathrm{~K}$ isotherm.

\subsection{Results for 2-propanol}

Experimental speed of sound data for 2-propanol with uncertainties are listed in Table 6 . To the best of our knowledge, only a single experimental data set at elevated pressure is available in the literature for this substance, reported by Dávila et al. ${ }^{38}$ Deviations of experimental speed of sound data from equation (6) are presented in Figure 7. The AAD of present speed of sound values from equation (6) is $0.14 \%$. Data reported by Dávila et al. ( $\mathrm{AAD}=0.20 \%$ ) with an experimental uncertainty of $0.013 \%$ coincide with present measurements at $300 \mathrm{~K}$. However, their data show a systematic offset at $250 \mathrm{~K}$ and $350 \mathrm{~K}$. It should be noted that their claimed sample purity was $99.9 \%$, whereas it was $99.99 \%$ here. Their data at $250 \mathrm{~K}$ and $350 \mathrm{~K}$ deviate more at low pressures and systematically approach the present results at high pressures. This behavior was not observed for the other alcohols, where their measurements follow a trend that is similar to the present work.

\subsection{Results for 1-butanol}

Experimental speed of sound data for 1-butanol with uncertainty values are given in Table 7. Deviations of the present experimental data from equation (6) and a comparison with experimental literature data is shown in Figure 8. Most of the authors reported data around $300 \mathrm{~K}$ and $350 \mathrm{~K}$, only one data set was found at $253 \mathrm{~K}$ and $393 \mathrm{~K}$. Data reported by Dávila et al. ${ }^{29}$ $(\mathrm{AAD}=0.09 \%)$ with an experimental uncertainty of $0.01 \%$ and a sample purity of $<99.8 \%$ are in excellent agreement with the present work within their temperature range from $253 \mathrm{~K}$ to 353 $\mathrm{K}$.

At $300 \mathrm{~K}$, data published by Wilson and Bradley, ${ }^{32}$ having an AAD of $0.15 \%$, an experimental uncertainty of $<0.56 \mathrm{~m} \mathrm{~s}^{-1}$ and a sample purity of $99.9 \%$, almost exactly match with the present data at low pressure and show a systematic offset at elevated pressure. Data by Shoitov and Otpushchennikov ${ }^{39}$ with an AAD of $0.26 \%$ and an experimental uncertainty of $0.04 \%$ also validate the present data at $350 \mathrm{~K}$. Plantier et al. ${ }^{30}(\mathrm{AAD}=$ $0.21 \%$ ) with an experimental uncertainty of $<0.2 \%$ and a sample purity of $<99 \%$ follow the same systematic trend along the isotherms $300 \mathrm{~K}$ and $350 \mathrm{~K}$. The deviations are largest around $10 \mathrm{MPa}$. 
Other authors also published speed of sound data for 1-butanol, exhibiting the following AAD: Carnevale and Litovitz, ${ }^{33}$ $0.40 \%$; Hawley et al. ${ }^{34} 0.41 \%$; Nematulloev et al., ${ }^{40} 1.32 \%$; Belinskii et al. ${ }^{41} 0.74 \%$. However these authors provided no information on experimental uncertainty or sample purity, but their data more or less validate the present results at some state points, but most of their data deviate by more than $0.7 \%$. As the data by Sysoev et al. ${ }^{42}$ for 1-butanol were available along other isotherms than the present work, their results were not considered for comparison.

Apart from the data by Plantier et al..$^{30}$ and Nematulloev et al., ${ }^{40}$ all the experimental results show a similar trend. The results by Plantier et al. ${ }^{30}$ exhibit a different pattern at $300 \mathrm{~K}$ and $350 \mathrm{~K}$ despite the fact that their data for methanol at $300 \mathrm{~K}$ are in an excellent agreement with the present measurements. This behavior could be a consequence of improper degassing of the sample fluid. Data by Nematulloev et al. ${ }^{40}$ scatter around the other experimental results, especially at $350 \mathrm{~K}$, indicating large uncertainties.

A thermodynamic model developed by Safarov et al. ${ }^{15}$ was compared with the experimental data along five isotherms. They calculated the speed of sound from density measurements of 1-butanol, showing large deviations at low temperatures, i.e. $250 \mathrm{~K}$ and $300 \mathrm{~K}$. However, at high temperatures and pressures these data match with the present measurements at some state points. For the $450 \mathrm{~K}$ isotherm, their model shows a good performance.

\section{Conclusion}

Speed of sound data of methanol, 1-propanol, 2-propanol and 1-butanol were sampled with the pulse-echo technique in the liquid and supercritical region. The provided data along seven isotherms cover a wide temperature range from $220 \mathrm{~K}$ to $500 \mathrm{~K}$ and a pressure of up to $125 \mathrm{MPa}$, where limited or inconsistent experimental literature data were available for the alcohols. The standard measurement uncertainty is $0.02 \mathrm{~K}$ for temperature, $0.002 \mathrm{MPa}$ for pressure below $10 \mathrm{MPa}, 0.02 \mathrm{MPa}$ for pressure between $10 \mathrm{MPa}$ and $100 \mathrm{MPa}, 0.06 \mathrm{MPa}$ for pressure above $100 \mathrm{MPa}$. This amounts up to $0.11 \%$ expanded uncertainty for speed of sound values, at a confidence level of $95 \%(k=2)$. A double polynomial equation was satisfactorily fitted to the speed of sound data for the alcohols. The absolute average uncertainty of experimental speed of sound data for the alcohols from their equations were $0.24 \%, 0.14 \%, 0.14 \%$ and $0.13 \%$, respectively. The accuracy of the present data is confirmed by a detailed comparison with the available literature sources.

\section{AUTHOR INFORMATION}

\section{Corresponding Author}

*Jadran Vrabec, Thermodynamics and Processes Engineering, Technical University of Berlin, 10623 Berlin, Germany, E-mail: vrabec@tu-berlin.de

\section{ACKNOWLEDGMENT}

The authors thank Dr. Gerhard Herres and Dr. Y. Mauricio MuñozMuñoz from department of Thermodynamics and Energy Technology (ThEt) University of Paderborn for fruitful discussions on fitting experimental data.

\section{REFERENCES}

1. Trusler, J. P. M. Physical Acoustics and Metrology of Fluids. Adam Hilger: Bristol, 1991.
2. Span, R. Multiparameter Equations of State-An Accurate Source of Thermodynamic Property Data. Springer: Berlin, 2000.

3. Thol, M.; Rutkai, G.; Köster, A.; Lustig, R.; Span, R.; Vrabec, J. Equation of State for the Lennard-Jones Fluid. J. Phys. Chem. Ref. Data 2016, 45, 23101.

4. Turns, S. R. Thermodynamics: Concepts and Applications. Cambridge University Press: Cambridge, 2006

5. Marczak, W.; Dzida, M.; Ernst, S. Determination of the thermodynamic properties of 1-propanol and 1-hexanol from speed of sound measurements under elevated pressures. High Temp. High Press. 2000, 32, 283-292.

6. Dubberke, F. H.; Rasche, D. B.; Baumhögger, E.; Vrabec, J. Apparatus for the measurement of the speed of sound of ammonia up to high temperatures and pressures. Rev. Sci. Instrum. 2014 85,84901 .

7. Thol, M.; Rutkai, G.; Köster, A.; Dubberke, F. H.; Windmann, T.; Span, R.; Vrabec, J. Thermodynamic properties of octamethylcyclotetrasiloxane. J. Chem. Eng. Data 2016, 61, 2580-2595.

8. Olah, G. A.; Goeppert, A.; Prakash, G. K. S. Beyond Oil and Gas: The Methanol Economy. Wiley-VCH: Weinheim, 2009.

9. Cheremisinoff, N. P.; Archer, W. L. Industrial Solvents Handbook. Marcel Dekker: New York, 2003.

10. Smallwood, I. M. Handbook of Organic Solvent Properties. Elsevier: New York, 1996.

11. Stoye, D.; Freitag, W. Paints, Coatings and Solvents. WileyVCH: Weinheim, 1998

12. Dincer, I. Refrigeration Systems and Applications. John Wiley \& Sons: New York, 2017.

13. Thol, M.; Dubberke, F. H.; Rutkai, G.; Windmann, T.; Köster, A.; Span, R.; Vrabec, J. Fundamental equation of state correlation for hexamethyldisiloxane based on experimental and molecular simulation data. Fluid Phase Equilib. 2016, 418, 133-151.

Thol, M.; Dubberke, F. H.; Baumhögger, E.; Vrabec, J.; Span, R. Speed of sound measurements and fundamental equations of state for octamethyltrisiloxane and decamethyltetrasiloxane. J. Chem. Eng. Data. 2017, 62, 2633-2648.

15. Safarov, J.; Ahmadov, B.; Mirzayev, S.; Shahverdiyev, A.; Hassel, E. P. Thermophysical properties of 1-butanol over a wide range of temperatures and pressures up to $200 \mathrm{MPa}$. J. Mol. Liq. 2015, 209, 465-479.

16. Lafitte, T.; Apostolakou, A.; Avendaño, C.; Galindo, A.; Adjiman, C. S.; Müller, E. A.; Jackson, G. Accurate statistical associating fluid theory for chain molecules formed from Mie segments. J. Chem. Phys. 2013, 139, 154504.

17. Postnikov, E. B.; Goncharov, A. L.; Cohen, N.; Polishuk, I. Estimating the liquid properties of 1-alkanols from $\mathrm{C} 5$ to $\mathrm{C} 12$ by FT-EoS and CP-PC-SAFT: Simplicity versus complexity. $J$. Supercrit. Fluids. 2015, 104, 193-203.

18. Cripwell, J.T.; Smith, S. A.; Schwarz, C. E.; Burger, A. J. SAFTVR Mie: Application to phase equilibria of alcohols in mixtures with n-alkanes and water. Ind. Eng. Chem. Res. 2018, 57, 9693 9706.

19. Lin, C. W.; Trusler, J. P. M. The speed of sound and derived thermodynamic properties of pure water at temperatures between (253 and 473) K and at pressures up to $400 \mathrm{MPa}$. J. Chem. Phys. 2012, 136, 94511.

20. Dubberke, F. H.; Baumhögger, E.; Vrabec, J. Burst design and signal processing for the speed of sound measurement of fluids with the pulse-echo technique. Rev. Sci. Instrum. 2015, 86, 54903.

21. Dubberke, F. H.; Riepold, M.; Baumhögger, E.; Vrabec, J. Speed of Sound of Oxygen in Supercritical States up to $500 \mathrm{~K}$ and 100 MPa. J. Chem. Eng. Data 2016, 61, 1632-1636.

Del Grosso, V. A.; Mader, C. W. Speed of Sound in Pure Water J. Acoust. Soc. Am. 1972, 52, 1442-1446.

23. Marczak, W. Water as a standard in the measurements of speed of sound in liquids. J. Acoust. Soc. Am. 1997, 102, 2776-2779.

24. Fujii, K.; Masui, R. Accurate measurements of the sound velocity in pure water by combining a coherent phase-detection technique and a variable path-length interferometer. J. Acoust. Soc. Am. 1993, 93, 276-282.

25. Wagner, W.; Pruß, A. The IAPWS formulation 1995 for the thermodynamic properties of ordinary water substance for general and scientific use. J. Phys. Chem. Ref. Data 2002, 31, 387-535.

26. Thol, M.; Dubberke, F. H.; Baumhögger, E.; Span, R.; Vrabec, J. 
Speed of Sound Measurements and a Fundamental Equation of State for Hydrogen Chloride. J. Chem. Eng. Data 2017, 62, 26332648.

27. Sun, T. F.; Ten Seldam, C. A.; Kortbeek, P. J.; Trappeniers, N. J.; Biswas, S. N. Acoustic and Thermodynamic Properties of Ethanol from 273.15 to $333.15 \mathrm{~K}$ and up to $280 \mathrm{MPa}$. Phys. Chem. Liq. 1988, 18, 107-116.

28.

De Reuck, K.; Craven, R. Methanol, International Thermodynamic Tables of the Fluid State. IUPAC, Blackwell Scientific Publication London 1993, 12.

29. Dávila, M. J.; Gedanitz, H.; Span, R. Speed of sound measurements of liquid C1-C4 alkanols. J. Chem. Thermodyn. 2016, 93, 157-163.

30. Plantier, F.; Daridon, J. L.; Lagourette, B. Nonlinear parameter (B/A) measurements in methanol, 1-butanol and 1-octanol for different pressures and temperatures. J. Phys. D. Appl. Phys. 2002, 35, 1063-1067.

31. Sun, T.; Biswas, S. N.; Trappenlers, N. J.; Ten, C. A. Acoustic and Thermodynamic Properties of Methanol from 273 to $333 \mathrm{~K}$ and at Pressures to $280 \mathrm{MPa}$. J. Chem. Eng. Data 1988, 33, 395398.

32. Wilson, W.; Bradley, D. Speed of Sound in Four Primary Alcohols as a Function of Temperature and Pressure. J. Acoust. Soc. Am. 1964, 36, 333-337.

33. Carnevale, E. H.; Litovitz, T. A. Pressure Dependence of Sound Propagation in the Primary Alcohols. J. Acoust. Soc. Am. 1955, 27, 547-550

34. Hawley, S.; Allegra, J.; Holton, G. Ultrasonic-Absorption and Sound-Speed Data for Nine Liquids at High Pressures. J. Acoust. Soc. Am. 1970, 47, 137-143.

35. Dzida, M.; Ernst, S. Speed of Sound in Propan-1-ol + Heptane Mixtures under Elevated Pressures. J. Chem. Eng. Data 2003, 48, 1453-1457.

36. Sysoev, V.; Otpushchennikov, N. F. Speed of sound in n-propyl alcohol in a broad temperature range and at pressures to 10,000 atm, Nauchnye Trudy - Kurskii Gosudarstvennyi Pedagogicheskii Institut. 1976, 81, 77-90.

37. Hagelberg, M. P. Ultrasonic-Velocity Measurements and B/A for 1-Propanol at Pressures to $10000 \mathrm{~kg} / \mathrm{cm}^{2}$. J. Acoust. Soc. Am. 1970, 47, 158-162.

38. Dávila, M. J.; Gedanitz, H.; Span, R. Speed of sound in saturated aliphatic alcohols (propan-2-ol, butan-2-ol, and 2-methylpropan1-ol) and alkanediols (ethane-1,2-diol, propane-1,2- and -1,3diol) at temperature between $253.15 \mathrm{~K}$ and $353.15 \mathrm{~K}$ and pressures up to $30 \mathrm{MPa}$. J. Chem. Thermodyn. 2016, 101, 199. 206.

39. Shoitov, Y. S.; Otpushchennikov, N. F. Pressure dependence of the speed of sound in liquids. Sov. Phys. J. 1968, 11, 129-130.

40. Nematulloev, U.; Belinskii, B.; Nozdrev, V. F. Study of the thermophysical and ultrasonic properties of certain aliphatic alcohols in the temperature range $20-230{ }^{\circ} \mathrm{C}$ and pressure range $1-1000 \mathrm{~kg} / \mathrm{cm}^{2}$. Thermophys Prop. Liq. 1970, 27-31.

41. Belinskii, B. A.; Ikramov, S. K.; Timofeev, V. I. A comprehensive study of the ultrasonic parameters, density, viscosity, and dielectric constant of n-butylol as functions of $\mathrm{P}, \rho$, and T. Izv. Akad. Nauk Srm. SSR, Ser. Fiz. 1971, 6, 57-60.

42. Sysoev, I. V.; Otpushchennikov, I. V.; Badalyan, A. L. Calculation of the speed of ultrasound in a series of $n$-alcohols in the pressure range to 10,000 atm, Nauchnye Trudy - Kurskii Gosudarstvennyi Pedagogicheskii Institut. 1976, 174, 146-151. 
Table 1. Specification of the fluids under study

\begin{tabular}{ccccc}
\hline fluid & CAS no. & formula & $\begin{array}{c}\text { purity } \\
\%\end{array}$ & supplier \\
\hline water & $7732-18-5$ & $\mathrm{H}_{2} \mathrm{O}$ & 99.99 & Merck \\
methanol & $67-56-1$ & $\mathrm{CH}_{3} \mathrm{OH}$ & $\geq 99.9$ & Merck \\
1-propanol & $71-23-8$ & $\mathrm{CH}_{3}\left(\mathrm{CH}_{2}\right)_{2} \mathrm{OH}$ & $>99.99$ & Sigma-Aldrich \\
2-propanol & $67-63-0$ & $\left(\mathrm{CH}_{3}\right)_{2} \mathrm{CHOH}$ & 99.99 & Honeywell \\
1-butanol & $71-36-3$ & $\mathrm{CH}_{3}\left(\mathrm{CH}_{2}\right)_{3} \mathrm{OH}$ & 99.97 & Alfa Aesar \\
\hline
\end{tabular}

Table 2. Coefficients of equations (6) and (7)

\begin{tabular}{lcccc}
\hline & methanol & 1-propanol & 2-propanol & 1-butanol \\
\hline$a_{10}$ & $2.9273035 \mathrm{E}-01$ & $3.7240367 \mathrm{E}-01$ & $3.4357521 \mathrm{E}-01$ & $3.8741741 \mathrm{E}-01$ \\
$a_{11}$ & $-4.9362767 \mathrm{E}-04$ & $-7.0452943 \mathrm{E}-04$ & $-6.5882505 \mathrm{E}-04$ & $-7.0483519 \mathrm{E}-04$ \\
$a_{12}$ & $-1.6073923 \mathrm{E}-15$ & $-4.2322239 \mathrm{E}-15$ & $1.3242749 \mathrm{E}-14$ & $-2.3742266 \mathrm{E}-15$ \\
$a_{20}$ & $1.6571387 \mathrm{E}-03$ & $5.4281481 \mathrm{E}-04$ & $3.7045380 \mathrm{E}-04$ & $2.4209078 \mathrm{E}-04$ \\
$a_{21}$ & $-6.0822729 \mathrm{E}-06$ & $-1.2660930 \mathrm{E}-06$ & $-8.0027071 \mathrm{E}-07$ & $-3.4303907 \mathrm{E}-07$ \\
$a_{22}$ & $5.3172980 \mathrm{E}-09$ & $5.6136655 \mathrm{E}-10$ & $1.8808617 \mathrm{E}-10$ & $1.2928960 \mathrm{E}-11$ \\
$a_{30}$ & $-2.9390275 \mathrm{E}-06$ & $-1.5511570 \mathrm{E}-06$ & $-3.4299590 \mathrm{E}-07$ & $-2.6850937 \mathrm{E}-07$ \\
$a_{31}$ & $1.3705131 \mathrm{E}-08$ & $7.3030049 \mathrm{E}-09$ & $1.9795323 \mathrm{E}-09$ & $1.6947649 \mathrm{E}-09$ \\
$a_{32}$ & $-1.5164299 \mathrm{E}-11$ & $-8.2036313 \mathrm{E}-12$ & $-2.3952863 \mathrm{E}-12$ & $-2.1260700 \mathrm{E}-12$ \\
$b_{0}$ & $-2.7825023 \mathrm{E}+03$ & $-5.7639323 \mathrm{E}+03$ & $-6.0142996 \mathrm{E}+03$ & $1.0472687 \mathrm{E}+03$ \\
$b_{1}$ & $9.4059302 \mathrm{E}+01$ & $1.5406467 \mathrm{E}+02$ & $1.5704867 \mathrm{E}+02$ & $2.3934220 \mathrm{E}+01$ \\
$b_{2}$ & $-7.7183950 \mathrm{E}-01$ & $-1.2413154 \mathrm{E}+00$ & $-1.2666427 \mathrm{E}+00$ & $-2.2274688 \mathrm{E}-01$ \\
$b_{3}$ & $3.1554647 \mathrm{E}-03$ & $5.0560116 \mathrm{E}-03$ & $5.1852877 \mathrm{E}-03$ & $8.8233517 \mathrm{E}-04$ \\
$b_{4}$ & $-7.1048564 \mathrm{E}-06$ & $-1.1305058 \mathrm{E}-05$ & $-1.1674734 \mathrm{E}-05$ & $-1.8391613 \mathrm{E}-06$ \\
$b_{5}$ & $8.4533549 \mathrm{E}-09$ & $1.3246123 \mathrm{E}-08$ & $1.3781109 \mathrm{E}-08$ & $1.9543988 \mathrm{E}-09$ \\
$b_{6}$ & $-4.2022846 \mathrm{E}-12$ & $-6.4022089 \mathrm{E}-12$ & $-6.7158197 \mathrm{E}-12$ & $-8.5207435 \mathrm{E}-13$ \\
$\mathrm{AAD}$ & $0.24 \%$ & $0.14 \%$ & $0.14 \%$ & $0.13 \%$ \\
\hline & & & & \\
\hline
\end{tabular}

Table 3. Uncertainty budget for the speed of sound measurements for the alcohols at a confidence level of $95 \%(k=2)$

\begin{tabular}{lccccc}
\hline source & type & $\begin{array}{c}\text { measuring } \\
\text { range }\end{array}$ & $\begin{array}{c}\text { standard } \\
\text { uncertainty }\end{array}$ & sensitivity coefficient ${ }^{a}$ & $\begin{array}{c}\text { relative expanded } \\
\text { uncertainty }^{a} \%\end{array}$ \\
\hline temperature & PT-25 & $84-693 \mathrm{~K}$ & $0.02 \mathrm{~K}$ & $\partial w / \partial T=2.2 \mathrm{~m} \mathrm{~s}^{-1} \mathrm{~K}^{-1}$ & 0.007 \\
& Keller-PAA-33X & $<10 \mathrm{MPa}$ & $0.002 \mathrm{MPa}$ & & 0.008 \\
pressure & Keller-PAA-33X & $<100 \mathrm{MPa}$ & $0.01-0.02 \mathrm{MPa}$ & $\partial w / \partial p=4.7 \mathrm{~m} \mathrm{~s}^{-1} \mathrm{MPa}^{-1}$ & 0.024 \\
& Honeywell TJE & $<200 \mathrm{MPa}$ & $0.06 \mathrm{MPa}$ & & 0.070 \\
time & handyscope HS5 & - & $0.002 \mu \mathrm{s}$ & $\partial w / \partial t=7.0 \cdot 10^{7} \mathrm{~m} \mathrm{~s}^{-2}$ & $\partial w / \partial \Delta l=5.9 \cdot 10^{4} \mathrm{~s}$ \\
path length & - & - & $7 \mu \mathrm{m}$ & & \\
\hline
\end{tabular}

${ }^{a}$ The values are for a typical state point at $350 \mathrm{~K}$ and $40 \mathrm{MPa}$. 
Table 4. Experimental speed of sound data for methanol at temperature $T$ and pressure $p^{a}$

\begin{tabular}{|c|c|c|c|c|c|c|c|}
\hline $\begin{array}{r}T \\
\mathrm{~K} \\
\end{array}$ & $\begin{array}{c}p \\
\mathrm{MPa} \\
\end{array}$ & $\begin{array}{c}w \\
\mathrm{~m} \mathrm{~s}^{-1}\end{array}$ & $\begin{array}{l}U(w) \\
\mathrm{m} \mathrm{s}^{-1}\end{array}$ & $\begin{array}{r}T \\
\mathrm{~K} \\
\end{array}$ & $\begin{array}{c}p \\
\mathrm{MPa} \\
\end{array}$ & $\begin{array}{c}w \\
\mathrm{~m} \mathrm{~s}^{-1}\end{array}$ & $\begin{array}{l}U(w) \\
\mathrm{m} \mathrm{s}^{-1}\end{array}$ \\
\hline 220.38 & 0.100 & 1387.9 & 1.1 & 349.99 & 19.881 & 1070.5 & 0.8 \\
\hline 220.41 & 1.023 & 1391.8 & 1.1 & 350.00 & 41.608 & 1186.3 & 0.9 \\
\hline 220.39 & 1.839 & 1395.3 & 1.1 & 349.95 & 60.336 & 1270.3 & 1.0 \\
\hline 220.96 & 10.454 & 1428.5 & 1.1 & 349.96 & 82.312 & 1356.2 & 1.0 \\
\hline 220.46 & 20.095 & 1467.9 & 1.1 & 349.96 & 99.275 & 1415.9 & 1.1 \\
\hline 220.39 & 40.357 & 1540.1 & 1.2 & 349.97 & 124.114 & 1495.1 & 1.2 \\
\hline 220.26 & 60.890 & 1606.5 & 1.3 & 399.94 & 0.798 & 770.2 & 0.6 \\
\hline 220.38 & 69.376 & 1631.5 & 1.3 & 399.94 & 1.015 & 772.5 & 0.6 \\
\hline 220.37 & 69.581 & 1632.2 & 1.3 & 399.94 & 2.112 & 784.4 & 0.6 \\
\hline 220.37 & 111.490 & 1746.8 & 1.4 & 399.93 & 5.110 & 815.0 & 0.6 \\
\hline 244.25 & 0.125 & 1294.5 & 1.0 & 399.92 & 9.339 & 854.2 & 0.6 \\
\hline 244.27 & 0.761 & 1297.5 & 1.0 & 399.92 & 21.337 & 948.3 & 0.7 \\
\hline 244.28 & 1.200 & 1299.5 & 1.0 & 399.89 & 42.375 & 1078.3 & 0.8 \\
\hline 244.30 & 1.980 & 1303.2 & 1.0 & 399.90 & 61.164 & 1172.4 & 0.9 \\
\hline 244.31 & 5.110 & 1317.8 & 1.0 & 399.91 & 81.158 & 1258.6 & 0.9 \\
\hline 244.32 & 9.712 & 1338.5 & 1.0 & 399.93 & 84.741 & 1273.4 & 1.0 \\
\hline 299.95 & 0.099 & 1096.3 & 0.8 & 399.73 & 98.358 & 1325.1 & 1.0 \\
\hline 299.94 & 0.963 & 1101.7 & 0.8 & 399.91 & 122.977 & 1409.6 & 1.1 \\
\hline 299.94 & 2.240 & 1109.5 & 0.8 & 450.22 & 2.562 & 568.3 & 0.5 \\
\hline 299.95 & 5.128 & 1126.7 & 0.8 & 450.19 & 4.910 & 608.8 & 0.5 \\
\hline 299.95 & 9.896 & 1153.8 & 0.9 & 450.22 & 14.312 & 730.4 & 0.6 \\
\hline 299.96 & 21.093 & 1212.5 & 0.9 & 450.20 & 20.347 & 794.1 & 0.6 \\
\hline 299.96 & 40.780 & 1302.9 & 1.0 & 450.18 & 39.568 & 943.1 & 0.7 \\
\hline 299.95 & 58.877 & 1375.6 & 1.0 & 450.17 & 59.905 & 1062.6 & 0.8 \\
\hline 299.94 & 80.229 & 1452.1 & 1.1 & 450.20 & 72.355 & 1124.9 & 0.8 \\
\hline 299.95 & 98.460 & 1511.3 & 1.2 & 500.06 & 9.535 & 412.8 & 0.4 \\
\hline 299.96 & 123.414 & 1585.5 & 1.3 & 499.98 & 19.828 & 611.1 & 0.5 \\
\hline 349.98 & 0.201 & 935.8 & 0.7 & 499.94 & 28.092 & 708.5 & 0.6 \\
\hline 349.98 & 0.970 & 941.9 & 0.7 & 500.06 & 30.612 & 733.2 & 0.6 \\
\hline 349.98 & 1.998 & 949.9 & 0.7 & 499.94 & 40.326 & 818.5 & 0.6 \\
\hline 349.98 & 4.864 & 971.5 & 0.7 & 499.94 & 60.313 & 955.4 & 0.7 \\
\hline 349.97 & 9.858 & 1006.8 & 0.7 & & & & \\
\hline
\end{tabular}

${ }^{a}$ The expanded uncertainties $U(w)$ for 0.95 level of confidence $(k=2)$ were calculated by considering the standard uncertainties: $u(T)=0.02 \mathrm{~K}, u(\Delta l)=7 \mu \mathrm{m}, u(t)=0.002 \mu \mathrm{s}$; for the pressure measurements, three pressure sensors were used with different operating ranges possessing the following $u(p)$ values: $0.002 \mathrm{MPa}$ for $p<10 \mathrm{MPa}, 0.02 \mathrm{MPa}$ for $p<100 \mathrm{MPa}$, and $0.06 \mathrm{MPa}$ for $p \geq 100 \mathrm{MPa}$. 
Table 5. Experimental speed of sound data for 1-propanol at temperature $T$ and pressure $p^{a}$

\begin{tabular}{|c|c|c|c|c|c|c|c|}
\hline $\begin{array}{l}T \\
\mathrm{~K} \\
\end{array}$ & $\begin{array}{c}p \\
\mathrm{MPa}\end{array}$ & $\begin{array}{c}w \\
\mathrm{~m} \mathrm{~s}^{-1}\end{array}$ & $\begin{array}{l}U(w) \\
\mathrm{m} \mathrm{s}^{-1}\end{array}$ & $\begin{array}{l}T \\
\mathrm{~K} \\
\end{array}$ & $\begin{array}{c}p \\
\mathrm{MPa} \\
\end{array}$ & $\begin{array}{c}w \\
\mathrm{~m} \mathrm{~s}^{-1}\end{array}$ & $\begin{array}{l}U(w) \\
\mathrm{m} \mathrm{s}^{-1}\end{array}$ \\
\hline 218.20 & 0.102 & 1512.0 & 1.2 & 350.08 & 20.259 & 1164.3 & 0.9 \\
\hline 218.26 & 0.875 & 1515.2 & 1.2 & 350.04 & 40.537 & 1273.0 & 1.0 \\
\hline 218.21 & 2.111 & 1520.8 & 1.2 & 350.03 & 52.186 & 1327.6 & 1.0 \\
\hline 218.26 & 5.018 & 1533.1 & 1.2 & 350.04 & 60.588 & 1364.3 & 1.0 \\
\hline 218.32 & 9.465 & 1551.0 & 1.2 & 400.05 & 0.307 & 847.6 & 0.6 \\
\hline 218.35 & 19.810 & 1591.6 & 1.2 & 400.05 & 0.947 & 854.9 & 0.6 \\
\hline 218.34 & 29.071 & 1626.6 & 1.3 & 400.05 & 2.155 & 867.0 & 0.6 \\
\hline 218.31 & 49.499 & 1698.1 & 1.3 & 400.03 & 4.879 & 893.3 & 0.7 \\
\hline 218.32 & 61.345 & 1736.4 & 1.4 & 400.07 & 9.768 & 936.6 & 0.7 \\
\hline 249.99 & 0.100 & 1382.6 & 1.1 & 400.07 & 19.974 & 1015.3 & 0.8 \\
\hline 249.99 & 0.177 & 1383.0 & 1.1 & 400.06 & 27.823 & 1068.3 & 0.8 \\
\hline 249.99 & 1.128 & 1387.7 & 1.1 & 399.98 & 30.784 & 1087.2 & 0.8 \\
\hline 250.01 & 2.296 & 1393.4 & 1.1 & 399.96 & 40.232 & 1142.9 & 0.9 \\
\hline 249.97 & 5.362 & 1408.3 & 1.1 & 399.98 & 50.284 & 1196.8 & 0.9 \\
\hline 249.94 & 9.322 & 1427.1 & 1.1 & 399.97 & 59.616 & 1242.9 & 0.9 \\
\hline 249.90 & 20.903 & 1478.7 & 1.1 & 450.12 & 1.081 & 636.4 & 0.5 \\
\hline 249.93 & 39.564 & 1553.9 & 1.2 & 450.12 & 2.181 & 653.9 & 0.5 \\
\hline 249.94 & 59.448 & 1625.8 & 1.3 & 450.11 & 5.172 & 697.0 & 0.5 \\
\hline 299.97 & 0.138 & 1199.6 & 0.9 & 450.11 & 9.782 & 754.2 & 0.6 \\
\hline 299.96 & 1.174 & 1206.0 & 0.9 & 450.10 & 20.385 & 860.0 & 0.7 \\
\hline 299.96 & 2.560 & 1214.3 & 0.9 & 450.11 & 30.113 & 938.6 & 0.7 \\
\hline 299.98 & 5.042 & 1228.8 & 0.9 & 450.13 & 40.189 & 1008.7 & 0.8 \\
\hline 299.98 & 9.515 & 1254.1 & 0.9 & 450.13 & 50.091 & 1069.5 & 0.8 \\
\hline 299.96 & 19.849 & 1308.7 & 1.0 & 500.31 & 4.798 & 438.4 & 0.4 \\
\hline 299.96 & 39.521 & 1400.6 & 1.1 & 500.32 & 9.558 & 542.3 & 0.4 \\
\hline 299.96 & 49.960 & 1444.6 & 1.1 & 500.32 & 19.968 & 690.2 & 0.6 \\
\hline 350.05 & 0.270 & 1030.8 & 0.8 & 500.31 & 30.851 & 799.1 & 0.6 \\
\hline 350.07 & 0.997 & 1036.3 & 0.8 & 500.28 & 39.800 & 870.0 & 0.7 \\
\hline 350.07 & 2.073 & 1044.4 & 0.8 & 500.30 & 50.346 & 946.6 & 0.7 \\
\hline 350.07 & 5.244 & 1067.5 & 0.8 & 500.31 & 60.509 & 1009.7 & 0.8 \\
\hline 350.06 & 9.697 & 1098.3 & 0.8 & 500.31 & 77.533 & 1102.4 & 0.8 \\
\hline
\end{tabular}

${ }^{a}$ The expanded uncertainties $U(w)$ for 0.95 level of confidence $(k=2)$ were calculated by considering the standard uncertainties: $u(T)=0.02 \mathrm{~K}, u(\Delta l)=7 \mu \mathrm{m}, u(t)=0.002 \mu \mathrm{s}$; for the pressure measurements, three pressure sensors were used with different operating ranges possessing the following $u(p)$ values: $0.002 \mathrm{MPa}$ for $p<10 \mathrm{MPa}$, and $0.02 \mathrm{MPa}$ for $p<100 \mathrm{MPa}$. 
Table 6. Experimental speed of sound data for 2-propanol at temperature $T$ and pressure $p^{a}$

\begin{tabular}{|c|c|c|c|c|c|c|c|}
\hline$T$ & $p$ & $w$ & $U(w)$ & $T$ & $p$ & $w$ & $U(w)$ \\
\hline $\mathrm{K}$ & $\mathrm{MPa}$ & $\mathrm{m} \mathrm{s}^{-1}$ & $\mathrm{~m} \mathrm{~s}^{-1}$ & $\mathrm{~K}$ & $\mathrm{MPa}$ & $\mathrm{m} \mathrm{s}^{-1}$ & $\mathrm{~m} \mathrm{~s}^{-1}$ \\
\hline 217.77 & 0.143 & 1445.1 & 1.1 & 349.97 & 1.915 & 966.0 & 0.7 \\
\hline 217.84 & 1.031 & 1449.0 & 1.1 & 349.97 & 5.044 & 992.5 & 0.7 \\
\hline 217.84 & 2.256 & 1454.8 & 1.1 & 349.97 & 9.682 & 1029.2 & 0.8 \\
\hline 217.88 & 6.084 & 1472.2 & 1.1 & 349.98 & 21.490 & 1111.7 & 0.8 \\
\hline 217.00 & 8.951 & 1489.1 & 1.1 & 349.98 & 42.396 & 1232.7 & 0.9 \\
\hline 216.95 & 24.689 & 1556.1 & 1.2 & 349.97 & 61.179 & 1324.0 & 1.0 \\
\hline 216.87 & 41.140 & 1619.7 & 1.3 & 349.97 & 81.377 & 1409.9 & 1.1 \\
\hline 216.89 & 60.566 & 1688.1 & 1.3 & 349.97 & 96.752 & 1469.0 & 1.1 \\
\hline 216.90 & 78.557 & 1746.2 & 1.4 & 349.94 & 123.510 & 1562.0 & 1.3 \\
\hline 216.97 & 98.400 & 1805.5 & 1.4 & 399.64 & 0.492 & 745.0 & 0.6 \\
\hline 216.96 & 121.241 & 1868.7 & 1.5 & 399.63 & 1.090 & 752.7 & 0.6 \\
\hline 249.84 & 0.159 & 1317.8 & 1.0 & 399.63 & 1.986 & 764.1 & 0.6 \\
\hline 249.86 & 0.992 & 1322.3 & 1.0 & 399.62 & 5.275 & 802.7 & 0.6 \\
\hline 249.87 & 2.039 & 1328.0 & 1.0 & 399.62 & 9.782 & 850.0 & 0.6 \\
\hline 249.85 & 4.937 & 1343.6 & 1.0 & 399.61 & 20.985 & 948.9 & 0.7 \\
\hline 249.85 & 9.128 & 1365.3 & 1.0 & 399.63 & 38.384 & 1071.2 & 0.8 \\
\hline 249.86 & 10.803 & 1373.6 & 1.1 & 399.63 & 61.965 & 1203.3 & 0.9 \\
\hline 249.85 & 19.905 & 1417.6 & 1.1 & 399.61 & 80.647 & 1291.3 & 1.0 \\
\hline 249.85 & 41.768 & 1512.2 & 1.2 & 399.60 & 97.607 & 1362.4 & 1.0 \\
\hline 249.85 & 59.235 & 1579.4 & 1.2 & 399.66 & 122.092 & 1454.2 & 1.2 \\
\hline 249.85 & 80.375 & 1653.1 & 1.3 & 450.06 & 1.639 & 499.2 & 0.4 \\
\hline 249.85 & 96.644 & 1705.5 & 1.3 & 450.04 & 2.190 & 512.0 & 0.4 \\
\hline 249.85 & 124.462 & 1787.6 & 1.5 & 450.02 & 22.115 & 792.1 & 0.6 \\
\hline 299.79 & 0.086 & 1132.8 & 0.8 & 449.97 & 42.419 & 957.3 & 0.7 \\
\hline 299.80 & 0.865 & 1138.2 & 0.9 & 449.98 & 61.580 & 1076.2 & 0.8 \\
\hline 299.81 & 2.097 & 1146.6 & 0.9 & 449.99 & 82.381 & 1183.6 & 0.9 \\
\hline 299.81 & 5.133 & 1166.5 & 0.9 & 450.00 & 97.646 & 1252.6 & 0.9 \\
\hline 299.79 & 9.677 & 1195.1 & 0.9 & 450.00 & 122.429 & 1352.4 & 1.1 \\
\hline 299.80 & 20.194 & 1256.1 & 1.0 & 500.17 & 7.568 & 371.1 & 0.3 \\
\hline 299.80 & 39.488 & 1353.7 & 1.0 & 500.15 & 9.582 & 424.0 & 0.3 \\
\hline 299.81 & 60.935 & 1447.1 & 1.1 & 500.11 & 22.653 & 636.6 & 0.5 \\
\hline 299.89 & 81.993 & 1527.9 & 1.2 & 500.25 & 40.483 & 812.4 & 0.6 \\
\hline 299.88 & 97.237 & 1581.4 & 1.2 & 500.27 & 61.769 & 961.8 & 0.7 \\
\hline 299.85 & 123.509 & 1665.9 & 1.4 & 500.27 & 80.461 & 1067.0 & 0.8 \\
\hline 349.93 & 0.138 & 950.4 & 0.7 & 500.27 & 98.305 & 1153.8 & 0.9 \\
\hline 349.94 & 1.099 & 958.9 & 0.7 & 500.28 & 123.715 & 1261.3 & 1.1 \\
\hline
\end{tabular}

${ }^{a}$ The expanded uncertainties $U(w)$ for 0.95 level of confidence $(k=2)$ were calculated by considering the standard uncertainties: $u(T)=0.02 \mathrm{~K}, u(\Delta l)=7 \mu \mathrm{m}, u(t)=0.002 \mu \mathrm{s}$; for the pressure measurements, three pressure sensors were used with different operating ranges possessing the following $u(p)$ values: $0.002 \mathrm{MPa}$ for $p<10 \mathrm{MPa}, 0.02 \mathrm{MPa}$ for $p<100 \mathrm{MPa}$, and $0.06 \mathrm{MPa}$ for $p \geq 100 \mathrm{MPa}$. 
Table 7. Experimental speed of sound data for 1-butanol at temperature $T$ and pressure $p^{a}$

\begin{tabular}{|c|c|c|c|c|c|c|c|}
\hline $\begin{array}{l}T \\
\mathrm{~K} \\
\end{array}$ & $\begin{array}{c}p \\
\mathrm{MPa}\end{array}$ & $\begin{array}{c}w \\
\mathrm{~m} \mathrm{~s}^{-1}\end{array}$ & $\begin{array}{l}U(w) \\
\mathrm{m} \mathrm{s}^{-1}\end{array}$ & $\begin{array}{l}T \\
\mathrm{~K} \\
\end{array}$ & $\begin{array}{c}p \\
\mathrm{MPa} \\
\end{array}$ & $\begin{array}{c}w \\
\mathrm{~m} \mathrm{~s}^{-1}\end{array}$ & $\begin{array}{l}U(w) \\
\mathrm{m} \mathrm{s}^{-1}\end{array}$ \\
\hline 218.17 & 0.100 & 1536.6 & 1.2 & 350.11 & 20.660 & 1199.6 & 0.9 \\
\hline 218.25 & 1.111 & 1540.5 & 1.2 & 350.10 & 40.651 & 1303.9 & 1.0 \\
\hline 218.26 & 2.129 & 1544.8 & 1.2 & 350.10 & 59.555 & 1388.7 & 1.1 \\
\hline 218.31 & 5.399 & 1558.2 & 1.2 & 350.09 & 80.590 & 1472.2 & 1.1 \\
\hline 218.28 & 9.570 & 1575.2 & 1.2 & 400.14 & 0.145 & 891.2 & 0.7 \\
\hline 218.22 & 19.695 & 1614.9 & 1.3 & 400.14 & 0.933 & 898.8 & 0.7 \\
\hline 217.92 & 39.005 & 1685.4 & 1.3 & 400.14 & 1.839 & 907.3 & 0.7 \\
\hline 218.12 & 59.881 & 1753.2 & 1.4 & 400.14 & 4.864 & 934.6 & 0.7 \\
\hline 218.18 & 79.839 & 1813.2 & 1.4 & 400.12 & 9.483 & 973.3 & 0.7 \\
\hline 250.00 & 0.067 & 1411.8 & 1.1 & 400.14 & 20.722 & 1055.9 & 0.8 \\
\hline 249.99 & 0.100 & 1412.0 & 1.1 & 400.14 & 36.029 & 1150.7 & 0.9 \\
\hline 249.99 & 2.060 & 1421.4 & 1.1 & 400.14 & 59.027 & 1269.1 & 1.0 \\
\hline 249.99 & 5.075 & 1435.7 & 1.1 & 400.14 & 79.223 & 1357.8 & 1.0 \\
\hline 249.98 & 9.057 & 1453.9 & 1.1 & 449.96 & 0.576 & 696.4 & 0.5 \\
\hline 249.98 & 22.437 & 1511.7 & 1.2 & 449.96 & 1.176 & 704.8 & 0.5 \\
\hline 250.01 & 40.124 & 1581.1 & 1.2 & 449.96 & 2.010 & 716.0 & 0.5 \\
\hline 249.98 & 58.985 & 1648.4 & 1.3 & 449.96 & 9.527 & 803.9 & 0.6 \\
\hline 249.98 & 79.282 & 1714.5 & 1.4 & 449.96 & 21.165 & 910.4 & 0.7 \\
\hline 300.04 & 0.101 & 1234.1 & 0.9 & 449.96 & 39.912 & 1043.3 & 0.8 \\
\hline 300.03 & 1.100 & 1240.0 & 0.9 & 449.96 & 59.899 & 1156.8 & 0.9 \\
\hline 300.03 & 2.196 & 1246.4 & 0.9 & 449.96 & 79.678 & 1251.8 & 0.9 \\
\hline 300.03 & 5.369 & 1264.5 & 1.0 & 499.96 & 1.636 & 472.8 & 0.4 \\
\hline 300.03 & 9.681 & 1288.1 & 1.0 & 499.96 & 2.336 & 490.0 & 0.4 \\
\hline 300.03 & 20.060 & 1341.4 & 1.0 & 499.96 & 4.923 & 544.0 & 0.4 \\
\hline 300.03 & 40.032 & 1432.5 & 1.1 & 499.96 & 7.243 & 586.7 & 0.4 \\
\hline 300.02 & 59.057 & 1509.0 & 1.2 & 499.96 & 9.870 & 626.9 & 0.5 \\
\hline 300.02 & 79.463 & 1582.8 & 1.2 & 499.95 & 19.314 & 741.4 & 0.6 \\
\hline 350.11 & 0.104 & 1067.1 & 0.8 & 499.91 & 25.968 & 806.2 & 0.6 \\
\hline 350.11 & 0.911 & 1073.1 & 0.8 & 499.95 & 40.048 & 918.1 & 0.7 \\
\hline 350.11 & 2.067 & 1081.4 & 0.8 & 499.96 & 60.162 & 1045.7 & 0.8 \\
\hline 350.11 & 4.569 & 1099.0 & 0.8 & 499.96 & 80.004 & 1149.3 & 0.9 \\
\hline 350.11 & 9.077 & 1129.2 & 0.8 & & & & \\
\hline
\end{tabular}

${ }^{a}$ The expanded uncertainties $U(w)$ for 0.95 level of confidence $(k=2)$ were calculated by considering the standard uncertainties: $u(T)=0.02 \mathrm{~K}, u(\Delta l)=7 \mu \mathrm{m}, u(t)=0.002 \mu \mathrm{s}$; for the pressure measurements, three pressure sensors were used with different operating ranges possessing the following $u(p)$ values: $0.002 \mathrm{MPa}$ for $p<10 \mathrm{MPa}$, and $0.02 \mathrm{MPa}$ for $p<100 \mathrm{MPa}$. 


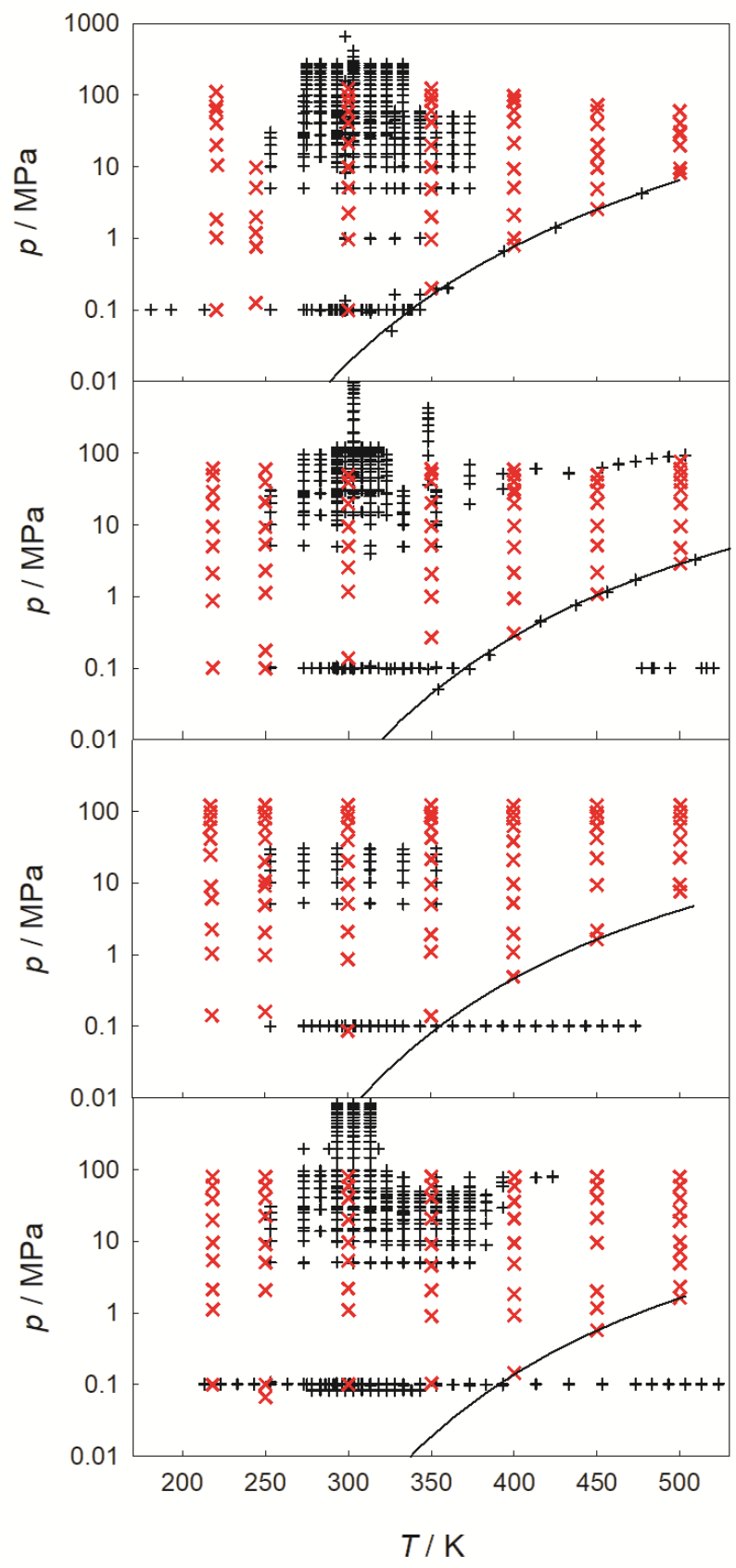

Figure 1. State points where speed of sound data were measured in this work $\times$ in comparison with experimental literature data + ; from top to bottom: methanol, 1-propanol, 2-propanol, 1-butanol. The solid line indicates the vapor pressure curve. Note that experimental literature data for 1-propanol and 1-butanol exist up to a pressure above $200 \mathrm{MPa}$ around 300 and $350 \mathrm{~K}$. 


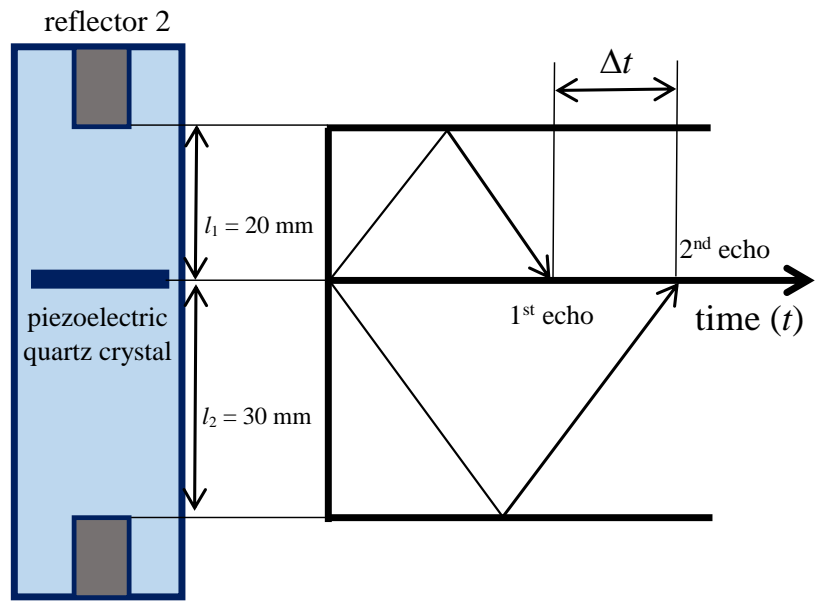

reflector 1

Figure 2. Measurement principle of the pulse-echo technique based on the single wave approach.

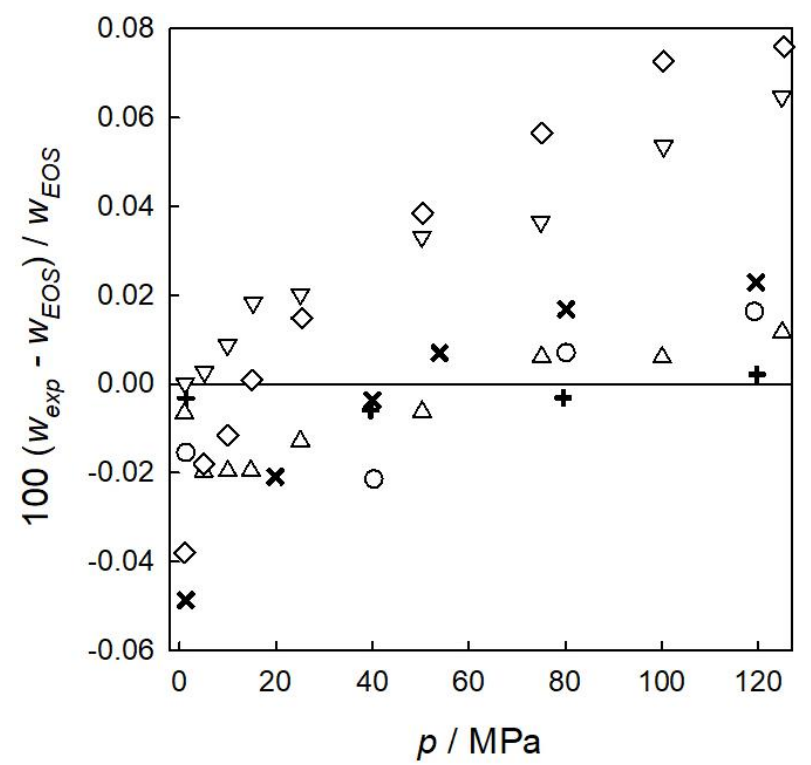

Figure 3. Deviation of experimental speed of sound data for water from the equation of state by Wagner and Pru $\beta,{ }^{25}$ experiment, this work: $\circ 300 \mathrm{~K},+350 \mathrm{~K}, \times 400 \mathrm{~K}$, experimental literature data by Lin and Trusler: ${ }^{19} \triangle 303 \mathrm{~K}, \nabla 373 \mathrm{~K}, \diamond 413 \mathrm{~K}$. 


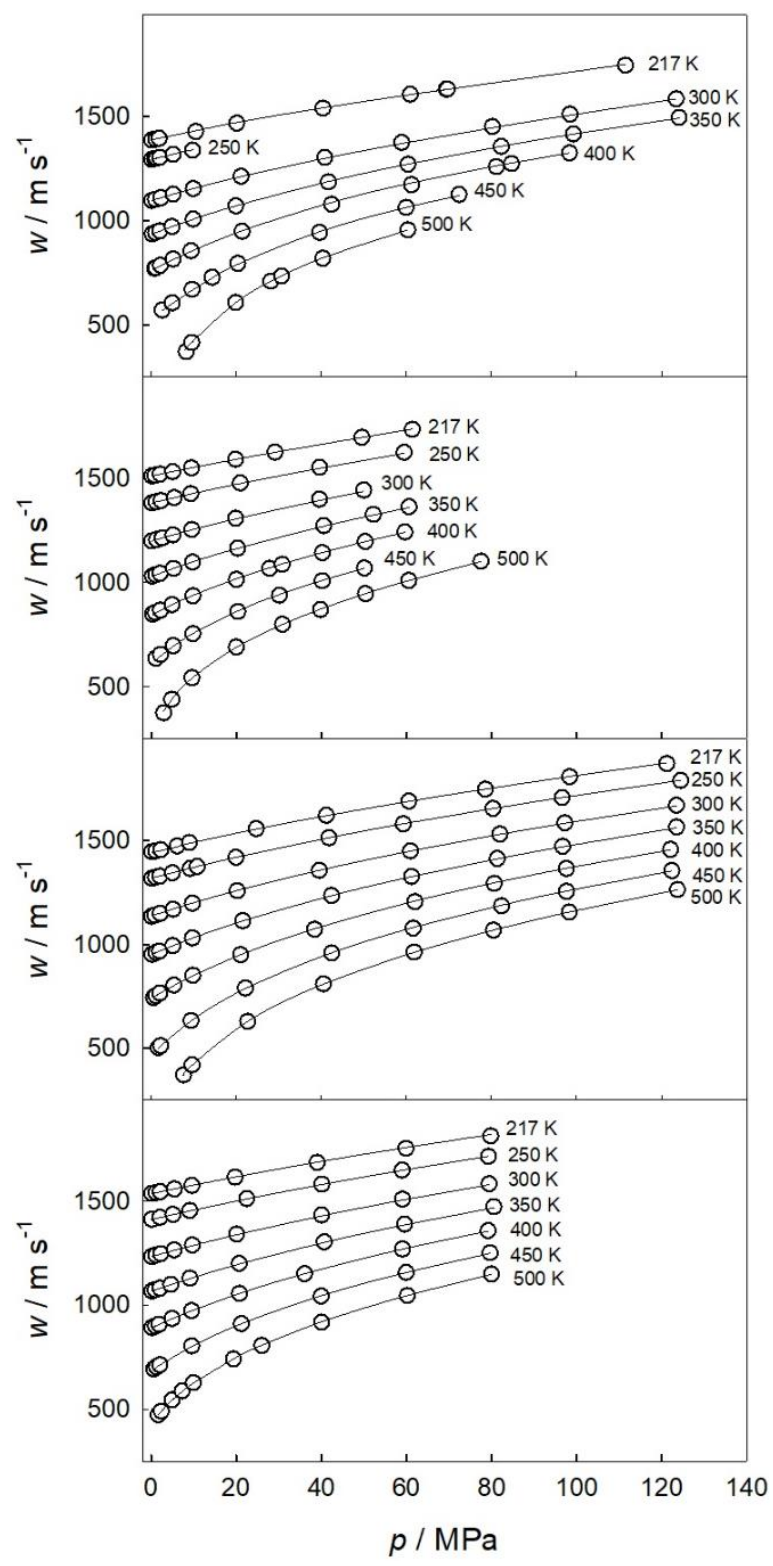

Figure 4. Speed of sound of the alcohols as a function of pressure along different isotherms: $\circ$ experiment, this work, - equation (6); from top to bottom: methanol, 1-propanol, 2-propanol, 1-butanol. 


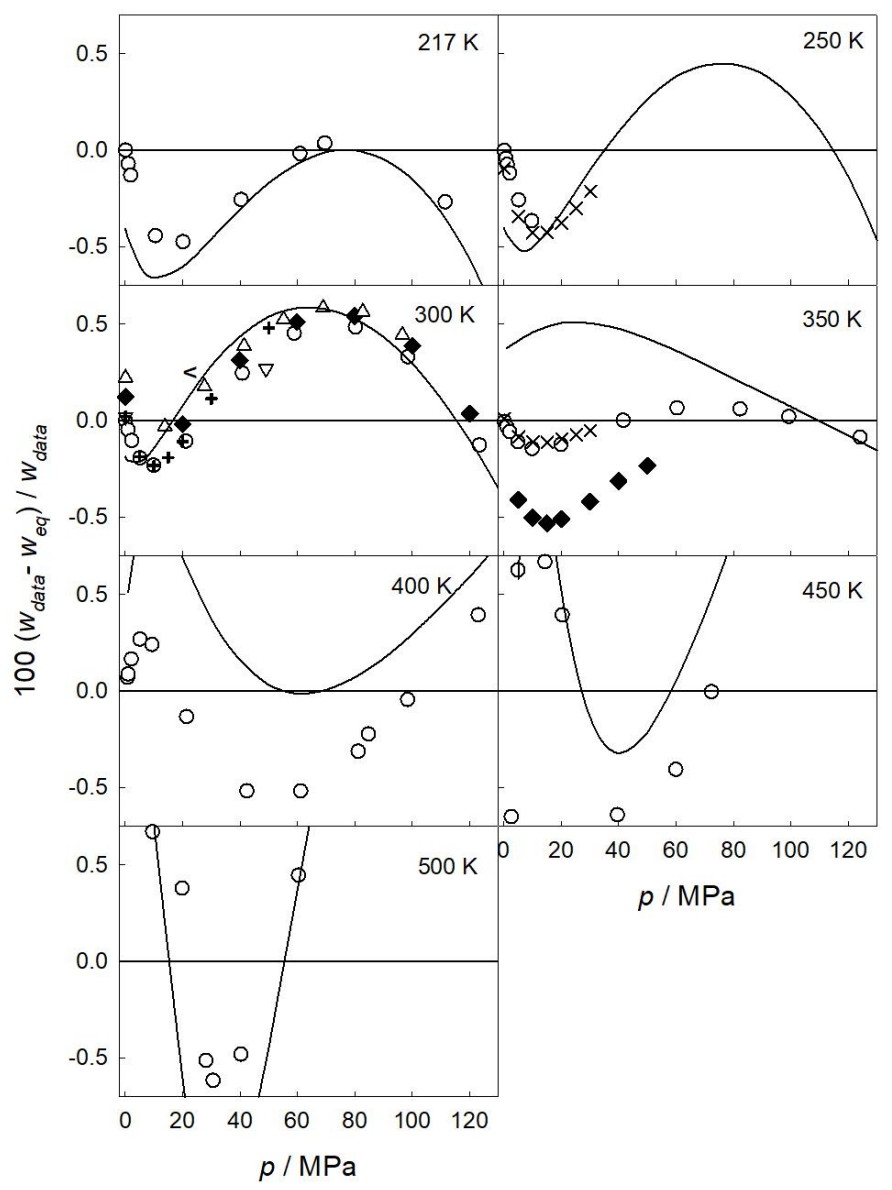

Figure 5. Deviation of speed of sound data from equation (6) for methanol: $~$ experiment, this work, - equation of state by De Reuck and Craven, ${ }^{28}$ experimental literature data: $\times$ Dávila et al., ${ }^{29}+$ Plantier et al.. ${ }^{30}$ Sun et al., ${ }^{31} \Delta$ Wilson and Bradley, ${ }^{32} \nabla$ Carnevale and Litovitz, ${ }^{33}<$ Hawley et al. ${ }^{34}$ 


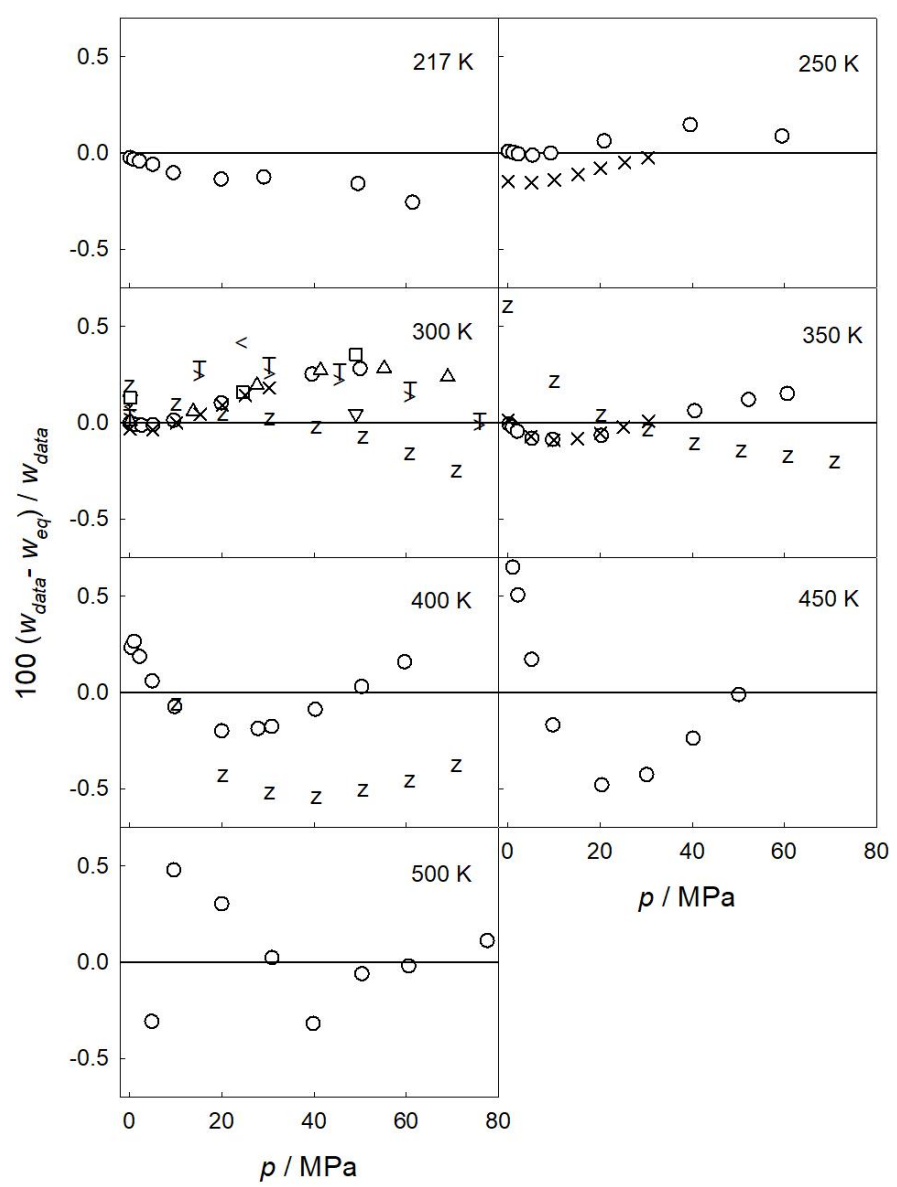

Figure 6. Deviation of speed of sound data from equation (6) for 1-propanol: o experiment, this work, experimental literature data: $\times$ Dávila et al. ${ }^{29} \triangle$ Wilson and Bradley, ${ }^{32} \nabla$ Carnevale and Litovitz, ${ }^{33}<$ Hawley et al., ${ }^{34}$ T Marczak et al., ${ }^{5}>$ Dzida and Ernst, ${ }^{35} \square$ Hagelberg, ${ }^{37}$ Z Sysoev and Otpushchennikov. ${ }^{36}$ 


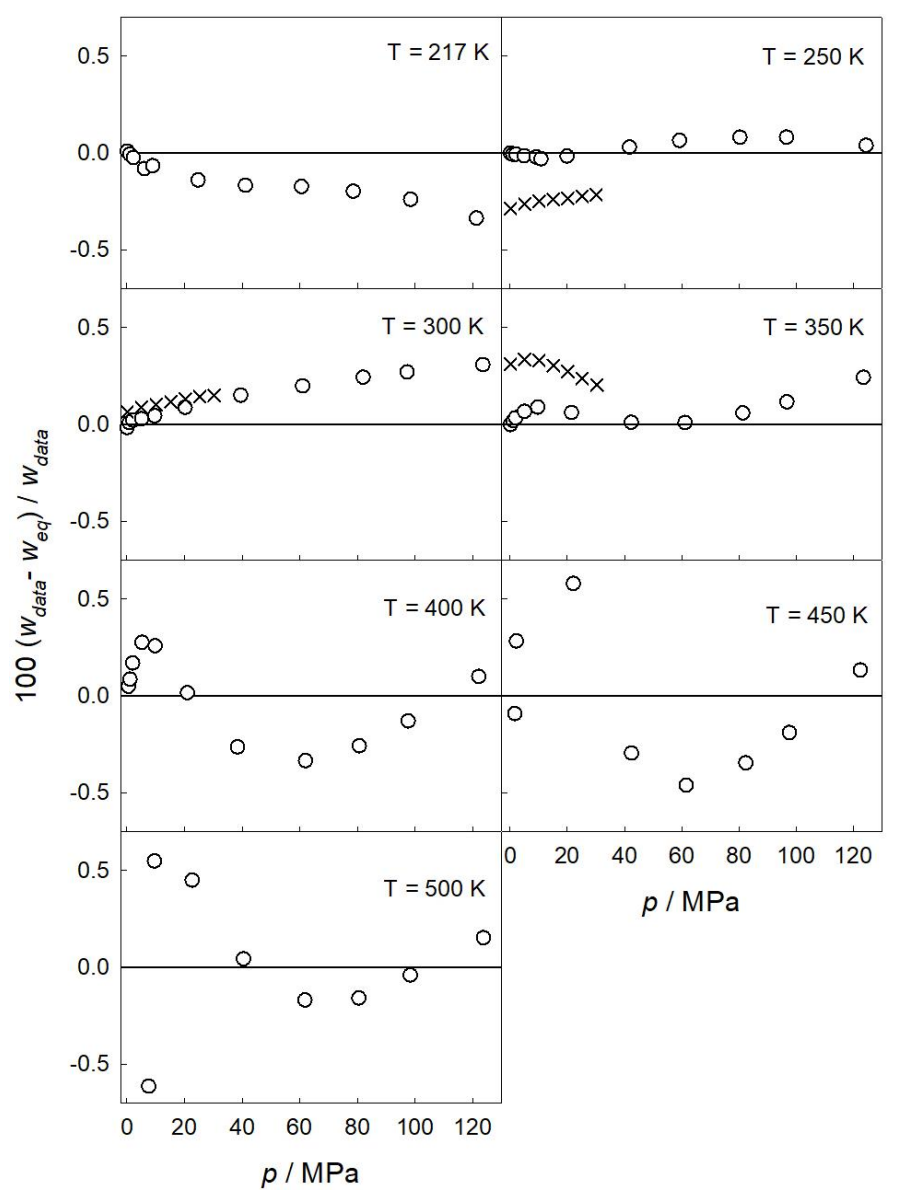

Figure 7. Deviation of speed of sound data from equation (6) for 2-propanol: o experiment, this work, experimental literature data: $\times$ Dávila et al. ${ }^{38}$ 


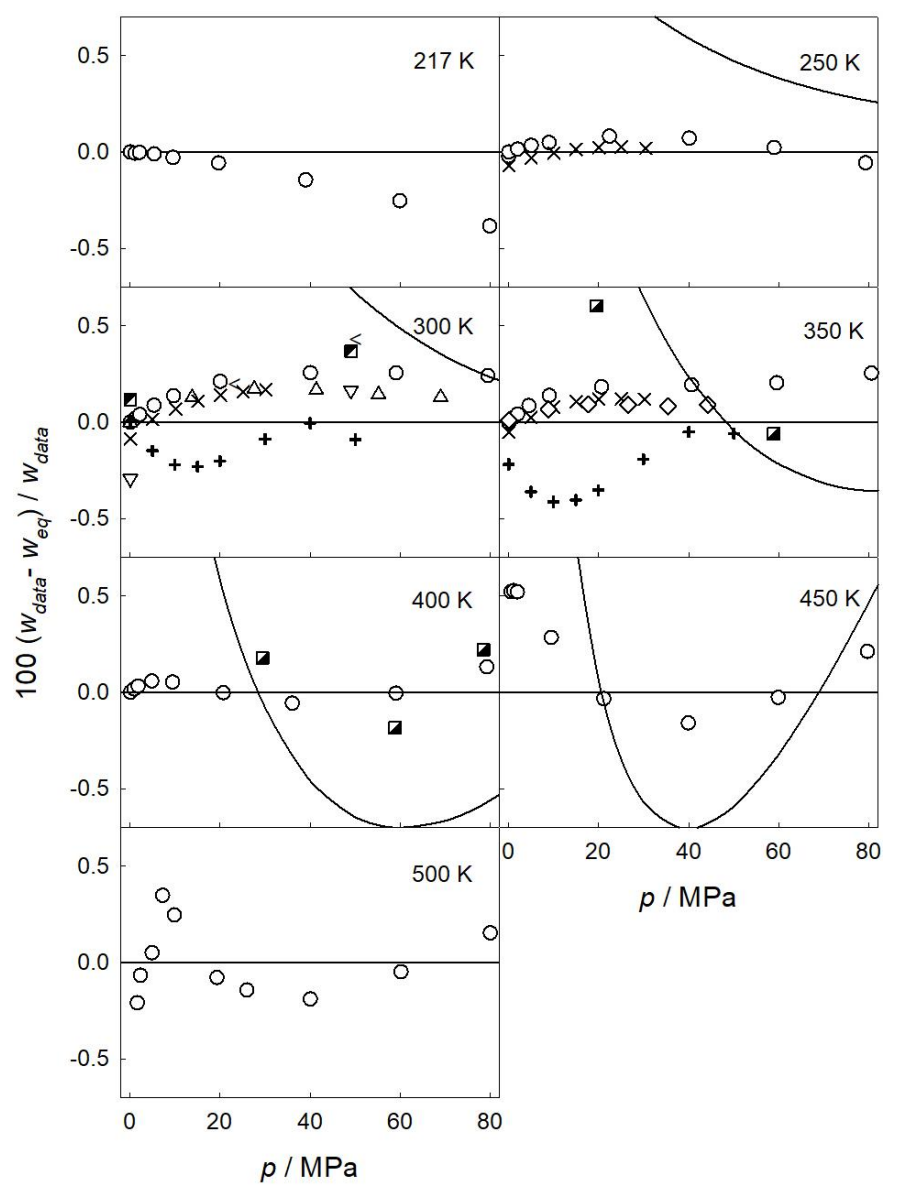

Figure 8. Deviation of speed of sound data from equation (6) for 1-butanol: o experiment, this work, - calculated speed of sound by Safarov et al., ${ }^{15}$ experimental literature data: $\times$ Dávila et al. ${ }^{29}+$ Plantier et al. ${ }^{30} \triangle$ Wilson and Bradley, ${ }^{32} \nabla$ Carnevale and Litovitz, ${ }^{33}<$ Hawley et al. ${ }^{34} \diamond$ Shoitov and Otpushchennikov, ${ }^{39} \boldsymbol{\nabla}$ Nematulloev et al., ${ }^{40} \boldsymbol{\nabla}$ Belinskii et al. ${ }^{41}$ 


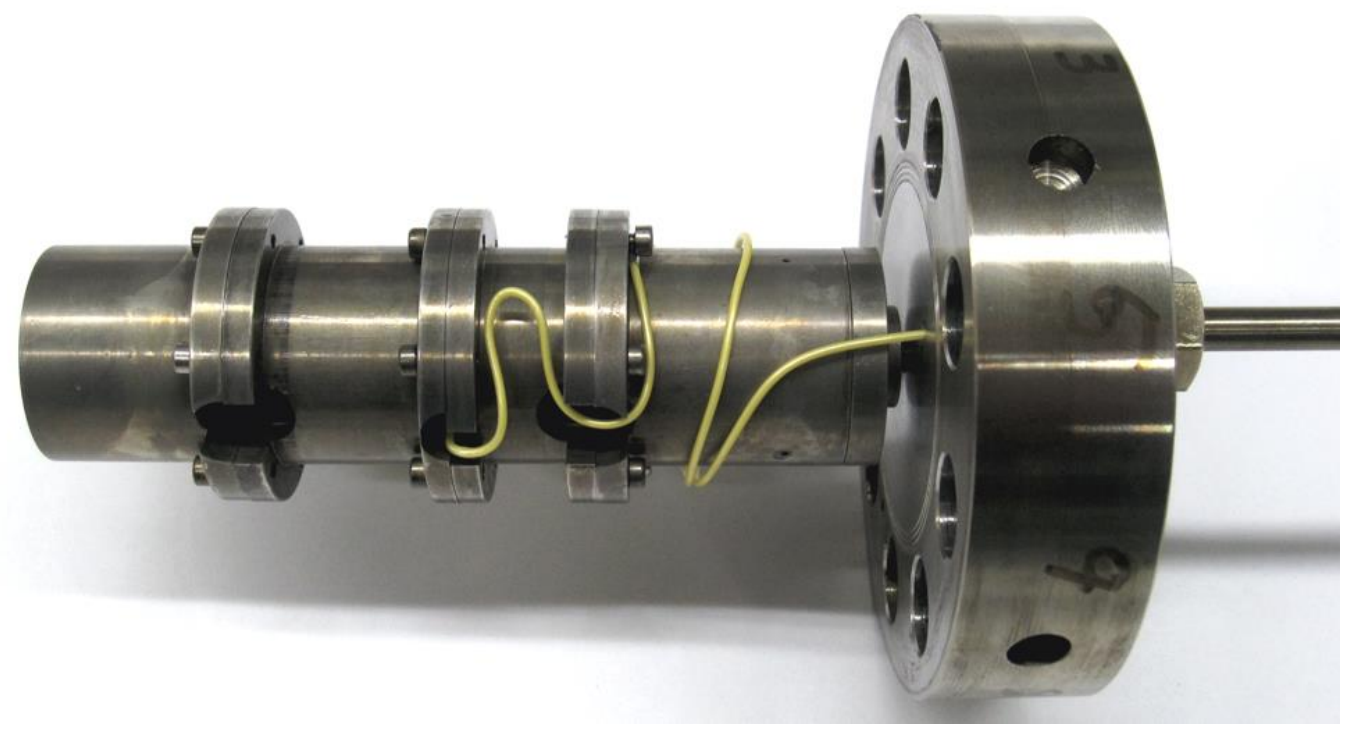

For table of contents only 